\title{
Flood Inundation Mapping and Hazard Assessment for Mitigation Analysis of Local Adaption Measures in Upper Ping River Basin, Thailand
}

Husnain Tansar ( $\sim$ husnaintansar2244@gmail.com )

The Hong Kong Polytechnic University https://orcid.org/0000-0001-6817-8436

Haseeb Akbar

King Mongkut's Institute of Technology North Bangkok: King Mongkut's University of Technology North Bangkok

Rana Ammar Aslam

University of Agriculture Faisalabad

\section{Research Article}

Keywords: Flood hazard, Mitigation, Upper Ping River Basin, Adaptation, Flood inundation

Posted Date: February 24th, 2021

DOI: https://doi.org/10.21203/rs.3.rs-230961/v1

License: (c) (i) This work is licensed under a Creative Commons Attribution 4.0 International License.

Read Full License 


\title{
1 Type of the Paper (Article)
}

\author{
2 Flood inundation mapping and hazard assessment for mitigation analysis of \\ 3 local adaption measures in Upper Ping River Basin, Thailand

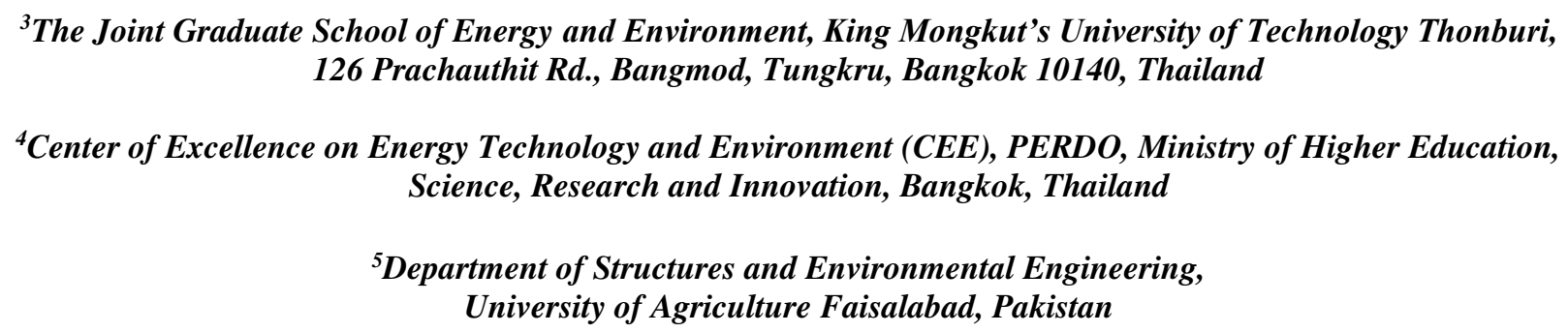

${ }^{3}$ The Joint Graduate School of Energy and Environment, King Mongkut's University of Technology Thonburi, 126 Prachauthit Rd., Bangmod, Tungkru, Bangkok 10140, Thailand

${ }^{4}$ Center of Excellence on Energy Technology and Environment (CEE), PERDO, Ministry of Higher Education, Science, Research and Innovation, Bangkok, Thailand

${ }^{5}$ Department of Structures and Environmental Engineering, University of Agriculture Faisalabad, Pakistan

24 Annual monsoon flooding phenomena have caused disastrous impacts on the Upper Ping River 25 basin and its inhabitants over the years. The existing administration set-up for flood mitigation and 26 adaptation measures lacks effective utilization of locally available resources for complete flood 27 protection. This study addressed this gap by flood hazard assessment at a lower administration 28 scale (sub-district level) and performance evaluation of local adaptation measures was performed. 29 1D and 2D hydrodynamic models were developed and calibrated against observed discharge and 30 water level (1D) and flood extent (2D), respectively. Flood inundation and hazard maps were 31 reproduced and categorized into different classes based on defined critical depths for 2, 5, 10, 25, 3250 and 100 years return periods. A maximum flood inundated area of $996.9 \mathrm{~km}^{2}$ (3.94\% of total 33 basin area) was simulated in a 100-year return period. The flood hazard results represent that the 34 largest flooded area categorized under "high hazard", followed by "very high hazard" and "low 35 hazard" categories, and least flooded area was classified under "medium hazard" category. The 36 current administration set-up for flood adaptation and mitigation needs to update based on an 37 integrated flood management approach to improve its effectiveness for future flood protection. 
38 Keywords: Flood hazard; Mitigation; Upper Ping River Basin; Adaptation; Flood inundation

\section{Introduction}

40 Annual pluvial and fluvial floods occurred during monsoon period in Thailand leads to disastrous 41 impacts on people, their properties, government and commercial infrastructure, and socio42 economic activities (Gale and Saunders 2013; Jular 2017). Besides these impacts, the floods 43 severely disturbed daily routine life of local people in rural and urban areas at a larger scale. 44 Generally, the flooding phenomena occurs in this region because of heavy monsoon rainfalls,

45 climate change impacts, conventional flood control and management strategies and resources, 46 topographical characteristics of floodplain areas and low level of education and technical training 47 of local residents about flood disaster preparedness (Haraguchi and Lall 2015). Considering local 48 structural and non-structural flood management resources, there is need to improve local flood 49 control and management framework based on available resources in order to improve its 50 effectiveness with the help of combined effort of all available resources.

52 Upper Ping River basin, a sub-region of Chao Phraya basin located in north of Thailand is home 53 to about $\sim 11.5$ million population, rice dominated region with a high economic growth rate. Large 54 fraction of population ( $90 \%$ ) in the basin lives in rural areas and exposed to river flooding due to 55 storage of flood water in rice fields (UN 2003; Reda et al. 2012; Komsai et al. 2016). The flooding 56 in Ping basin is associated to heavy monsoon rainfall, tropical storms, typhoons, and land-use 57 changes (Wood and Ziegler 2008; Gale and Saunders 2013; Komsai et al. 2016; Takata and 58 Hanasaki 2020). Available literature on climate change assessment in the basin though very 59 limited, reports significant increase in temperature extremes and insignificant decrease in mean 60 and extreme precipitation in the basin (Sharma and Babel 2013; Masud et al. 2016; Saengsawang 61 et al. 2017). Several other studies on floods highlight the occurrence of extreme events in past in 62 1994, 1995, 1996, 2001, 2003, 2005, and 2011 (Wood and Ziegler 2008; Gale and Saunders 2013; 63 Komsai et al. 2016). For example, the 2011 flood in Thailand caused heavy damage to agriculture, 64 transport, fishery, tourism and industry. The overall economic losses in all sectors amount to 65 around \$200 million (Taesombat and Sriwongsitanon 2010). Such huge losses necessitate 66 evaluation of the hazard potential to flood depth and spatial extent. 
68 Flood hazard potential can be mapped in multiple ways such as by conducting field surveys for 69 historical flood investigations or using remotely sensed imagery, employing hydrological and 70 hydrodynamic models, or both (Shehata and Mizunaga 2018). However hydrodynamic modeling 71 approach is more promising, it uses terrain data to simulate spatiotemporal variations of depth of 72 flood water (hazard potential) (Yalcin 2020). Hydrodynamic modeling can be one-dimensional 73 (1D) or two dimensional (2D) (Abdessamed and Abderrazak 2019; Mahmood et al. 2019; Nastiti 74 et al. 2018; Masood and Takeuchi 2012). One dimensional is most commonly used for flood hazard 75 mapping however possess one major limitation that it calculates spatial extent of the flood water 76 between two cross-sections using linear interpolation that introduces uncertainty in the interpolated 77 maps (De Kok and Grossmann 2010; Sarhadi et al. 2016; Yin et al. 2013; Zhang et al. 2021). Two

78 dimensional models have capability to overcome this problem using sophisticated numerical 79 methods such as finite difference and finite element. They can calculate flood depth, spatial extent 80 and velocity for each node and time step (Bates and De Roo 2000; Mani et al. 2014; Patel et al. 2017;

81 Farooq et al. 2019).

83 Flood adaptation and mitigation measures are normally applied under different administration

84 scales (e.g., National Government Level, Local Government Level, Local Community Level) in 85 Thailand and mostly they only work within their jurisdiction. This conventional flood control and 86 management set-up are not effectively working for potential flood risk reduction over the 87 vulnerable floodplain areas, as mostly, one administration department or stakeholder completes 88 his assigned task only, due to which the flood risk is transferred or redistributed to neighboring 89 regions or lower floodplain areas (Lebel et al. 2011; Manuta et al. 2006; Lebel and Sinh 2009; 90 Nikitina 2007). Considering this situation, there is a need to re-think about flood control and 91 management strategies that should cover this deficiency and produce combined effect of all 92 resources for potential flood risk reduction over the region. To cover this gap, this study developed 93 and applied 1D-2D hydrodynamic models for flood inundation mapping and hazard assessment 94 for evaluation of available mitigation options in Upper Ping River basin.

95

96 Synthesis of the literature available on flood hazard mapping and evaluation of mitigation options

97 in Ping River basin reveals a major drawback. The scope of almost all the studies was limited to 98 assess flood characteristics using simple rainfall-runoff and 1D hydrodynamic models (e.g., Wood 
99 and Ziegler 2008; Mapiam and Sriwongsitanon 2009; Sriwongsitanon 2010; Boonrawd and

100 Jothityangkoon 2015; Komsai et al. 2016) and no study has yet been conducted for flood hazard

101 mapping at sub-district scale for improvement in potential of locally available mitigation options.

102 The authors argue that "integrated flood management framework" is the absolute omission of

103 current flood adaptation and mitigation application system that can mislead future flood mitigation

104 planning and limit the efficiency of flood protection system. This is actually happening in the basin

105 during past one decade and bringing public concerns about the performance of the existing

106 protection measures (Jarungrattanapong and Manasboonphempool 2011). Since integrated flood

107 management approach has potential to boost the current flood protection system and its impacts

108 would be beneficial for local residents for future floods.

109

110 Considering its importance this study evaluates the flood hazard potential at sub-district level in 111 Upper Ping River basin using 1D and 2D hydrodynamic models for mitigation assessment of local

112 available flood mitigation resources and recommendations for these resources for improvement in

113 future floods. The paper is divided into five sections; section 1 details characteristics of the Upper

114 Ping River basin; section 2 comprehends materials and methods; section 3 describes results and

115 discussion parts, and section 4 includes conclusions.

116

117 Study area and data description

118 The Ping river is one of the main tributaries among four rivers of Chao Phraya river that originates

119 from Chiang Dao district in the north of Thailand, flows through the central and lower region of

120 Thailand before discharging into the Gulf of Thailand. The Upper Ping River basin is located

121 between Wang and Salween river basin of Myanmar (Jothityangkoon et al. 2013). The Basin

122 covers a catchment area of $25300 \mathrm{~km}^{2}$ with several mountain ranges in Chiang Mai and Lamphun

123 provinces (Figure 1). The Ping river passes from north to south in the center of Chiang Mai city,

124 the most popular tourist place in the northern region of Thailand. The Bhumipol Dam that is

125 constructed in Tak province, divides the upper and lower ping river basin, has a maximum storage

126 capacity of 13462 million $\mathrm{m}^{3}$. The basin generates an average annual runoff of 6815 million $\mathrm{m}^{3}$

127 (Mapiam and Sriwongsitanon 2009) with average annual rainfall and potential evaporation of

$1281174 \mathrm{~mm}$ and $1661 \mathrm{~mm}$. Most of the basin's climate is tropical and has a long rainy season (May -

129 October), and $90 \%$ of the annual rainfall occurs during rainy season. The weather of the study 
130 basin is influenced by the Southwest and Northeast monsoon. The topography of the basin is based 131 on steep and complex mountainous regions with elevation ranges from $224 \mathrm{~m}$ to $2575 \mathrm{~m}$. The 132 highest proportion of land-use consists of forest (70\%), followed by urban (12\%), and only $6 \%$

133 area is covered under plantation. Multiple flood episodes have been observed over the last two 134 decades during the monsoon period in the Upper ping basin including 1994, 1995, 2001, 2005,

1352009,2010 , and 2011 with the highest flood level of 4.94m in 2011 year at P.1 station (Boonrawd 136 and Jothityangkoon 2015).

137 The basin has a well-distributed network of rain gauges (90) and streamflow stations (44), but 138 many of them are not functional or do not have sufficient data, and only the meteorological and 139 hydrological data from 17 rain gauges and 2 flow gauges (respectively) have used for the flood 140 hazard assessment and recommendations of appropriate flood mitigation and adaption measures 141 at this region that could be practically implementable considering locally available resources, as

142 represented in Figure 1. The detailed description of meteorological and hydrological stations is 143 mentioned in Table 1 and Table 2. The digital elevation model (DEM), which is used to prepare 144 for floodplain bathymetry for the 2D-hydrodynamic model, is downloaded from 145 https://earthexplorer.usgs.gov/ with a resolution of $30 \mathrm{~m} \times 30 \mathrm{~m}$. Due to the larger floodplain area 146 and to optimize computational time, the $30 \mathrm{~m}$ dem resolution was resampled into $85 \mathrm{~m}$ for the 147 preparation of floodplain bathymetry.

148

149

[Figure 1.]

150

151

152

[ Table 1.]

153

154

[Table 2.]

\section{Methods}

\section{Methodological Framework}


157 The methodology of the study based on the development of hydrological and hydrodynamic

158 models, forcing of input data, followed by simulations, calibration and validation, and analysis of 159 post-simulation flood results and its evaluation for further scenarios. The methodological 160 framework consists of three sections (a) 1D-2D coupled model development, (b) 1D and 2D model 161 calibration and validation, and (c) flood hazard assessment and mitigation measures. Figure 2 162 represents the step-by-step methodological framework adopted in this study.

\section{[Figure 2.]}

\section{$1641 D$ Hydrodynamic Model Set-up}

165 The 1D hydrodynamic model (MIKE 11) applied in this study, which has six editors are mutually 166 interlinked with each other and used for river model development by defining sub-basins, cross167 sections, boundary conditions, network layout, hydrodynamic parameters and simulation 168 specifications (Tansar et al. 2020). All editors of the MIKE 11 model are dynamically interlinked 169 and controlled by the simulation editor. Also, this editor used to define simulation specifications 170 including simulation model, simulation mode, runoff and hotstart files, simulation time-period and 171 time-step, and saving time-step. The river network is defined in network editor. In upper ping river 172 basin, the ping river is the main tributary that starts from Doi Thuai in Chiang Dao district, passes 173 from Chaing Mai, Lamphun and Tak provinces and inflowed to Bhumipol Dam. The main rivers 174 including Ping river, Mae Nam Taeng, Mae Nam Rim, Mae Nam NGAT, Mae Nam Kuang, Mae 175 Wang, Mae Klang, Mae Nam Tha and Mae Li's have defined with their total river lengths of 283 $176 \mathrm{~km}, 155 \mathrm{~km}, 56 \mathrm{~km}, 82 \mathrm{~km}, 115 \mathrm{~km}, 116 \mathrm{~km}, 46 \mathrm{~km}, 78 \mathrm{~km}$ and $212 \mathrm{~km}$, respectively. The river 177 geometry is defined as $\mathrm{X}-\mathrm{Z}$ coordinates (from left bank) in the cross-section editor and the mean 178 distance between two adjacent cross-sections was $2 \mathrm{~km}$. The 19 sub-basins with corresponding 179 rainfall stations (17), and rainfall and evaporation data are defined in runoff editor for runoff 180 generation. The simulated runoff of each sub-basin is laterally distributed along the corresponding 181 river in network editor, where the runoff and network editors are dynamically interlinked by 182 defining sub-basins along with corresponding rivers with upstream and downstream boundaries. 183 The upstream river boundaries as discharge are defined at " 0 " chainage and only one downstream 184 boundary as water level is defined at the end of Ping river (P.73 station, Figure 1). The 185 hydrodynamic parameters including water depth, discharge, bed resistance, and output parameters 186 with their initial conditions are defined in the hydrodynamic editor. The bed resistance is the main 
187 parameter that is defined as local (horizontal and vertical) and global roughness coefficient

188 (Manning' n) for discharge and water level calibration.

\section{2D Hydrodynamic Model Set-up}

190 The floodplain boundary is defined in MIKE 21 model as rectangular bathymetry with $85 \mathrm{~m} \times 85$

$191 \mathrm{~m}$ resolution, considering the river network and 100-year observed flood extent. With this

192 resolution, the $2 \mathrm{D}$ hydrodynamic model simulates discharge and water level at every $85 \mathrm{~m}$

193 distance. Apart from bathymetry as the main input parameter, several other parameters including

194 boundaries, simulation specifications, initial surface elevation, flood and dry depths, resistance

195 and eddy viscosity and infiltration are required for flood inundation simulation. Only the flood

196 plain resistance as roughness coefficient (n) of 0.04 was used for flood extent calibration and

197 remaining parameters were considered as default. The simulation time step and results saving time

198 step were 5 seconds and 12 hours, respectively.

199 1D-2D Coupled Modeling Package

200 The calibrated 1D-hydrodynamic model (MIKE 11) and 2D-hydrodynamic model (MIKE 21) are 201 dynamically coupled through MIKE Flood to reproduce flood inundation results. In order to 202 capture flood inundations in MIKE Flood, the weir equation is defined at the lateral links between 203 both river banks (left and right) and floodplain, and the flood volume is overflowed to the 204 floodplain through these links when the water level rises over the bank elevation in the 1D-

205 hydrodynamic model. The flood extent and depth are based on the magnitude of flooded volume, 206 overflow location and topography of floodplain located around both river banks. In addition, the 207 overflow can travel from river to floodplain and vice versa in MIKE Flood based on the 208 topographical characteristics of the river banks, floodplain and the magnitude of flooded volume.

209 The detailed theoretical background of 1D-hydrodynamic model (MIKE 11), 2D-hydrodynamic 210 model (MIKE 21) and coupling package (MIKE Flood) are explained in Tansar et al., 2020.

\section{Flood Frequency Analysis}

212 The Gumbel probability distribution was applied on meteorological, hydrological and water level

213 data of past 30 years to find the extreme values for different return periods. The gumble distribution 214 was selected among other probability distributions (e.g. normal, log-normal, Pearson type-III, log- 
215 Pearson Type-III and extreme value Type I (EV I) because of its better performance and it has

216 been extensively applied and reported over the last few years in different published case studies of 217 Thailand (Tingsanchali and Karim 2010; Shrestha and Lohpaisankrit 2017; Tansar et al. 2020)

\section{Gumbel Distribution}

219 The cumulative distribution function (cdf) of the of Gumbel distribution (maximum) is defined as 220 represented in Eq. (1).

221

222

$$
F(x)=\exp [-\exp (-y)]=e^{-e^{-y}}
$$

223

224 Where function $\boldsymbol{F}(\boldsymbol{x})$ denotes the probability distribution function of random variable $\boldsymbol{x}$ and $y$ 225 represents the reduced variable.

226 Eq. (2) denotes the relation between probability of exceedance of excluded events and return $227 \operatorname{period}(T)$.

228

229

$$
F_{1}(x)=1-F(x)=\frac{1}{T}
$$

230 Eq. (3) is established by following Eq. (1) and (2).

231

232

$$
\frac{1}{T}=1-e^{-e^{-y}}
$$

233

234 The reduced variable $\boldsymbol{y}$ is calculated by using Eq. (4).

235

236

$$
y=-\ln \left\{\ln \left[\frac{T}{(T-1)}\right]\right\}
$$

237

238 The statistical variate is computed with Eq. (5).

239

240

$$
y=\overline{y_{n}}+K \cdot \sigma_{n}
$$


242 Eq. (6) is applied to calculate frequency factor $(K)$ in which $\overline{y_{n}}$ is a Gumbel's reduced mean 243 variable and $\sigma_{n}$ is the standard deviation.

$$
K=\frac{y-\overline{y_{n}}}{\sigma_{n}}=\frac{\left(-\ln \left\{\ln \left[\frac{T}{(T-1)}\right]\right\}\right)-\overline{y_{n}}}{\sigma_{n}} \ldots
$$

246

247 More technical details of Gumbel distribution method and its application can be found in Onen 248 and Bagatur 2017.

\section{Design Peak Hydrograph}

250 Design peak hydrographs of meteorological and hydrological data of different return periods are 251 derived based on the annual maximum values estimated by frequency analysis of past 30 years of

252 measurements. The design peak flood hydrographs of different return periods $(2,5,10,25,50$, and 253 100-year) are developed based on non-dimensional hydrographs (Tingsanchali and Karim 2010).

254 The 2011 flood year is selected for the development of designed hydrograph. A single annual 255 maximum value is provided by frequency analysis of selected flood year that is used to generate 256 the continuous time series of the entire flood year. The time series of selected flood year is divided 257 by maximum observed value to normalize the non-dimensional hydrograph. Following this 258 procedure, the peak of the non-dimensional value should be equal to unity. The time series of non259 dimensional hydrograph is multiplied with the annual maximum value to generate the designed 260 peak flood hydrograph. The same procedure was repeated for each return period for the 261 hydrographs' construction of all stations and boundary conditions (Brunner et al. 2016; Mediero 262 et al. 2010).

\section{Categorization of Flood hazard Assessment}

264 The flood hazard has been classified into different categories for spatial flood risk assessment, and 265 this information leads to in-depth understanding of severity of flood problems that can be avoided 266 in future by following proper flood mitigation and adaptation measures (Shrestha and 267 Lohpaisankrit 2017). Multiple factors such as flood depth, duration of flood and flood velocity are 268 considered for estimation of flood hazard assessment during flood study. These parameters are 
269 considered based on the topographical characteristics of study area, especially of floodplain 270 regions and also flood conditions. The present study only consider flood depth for classification 271 of flood hazard as the topography of flooding region is quite flat and flood wave velocity can be 272 negligible.

273 The detailed classification of flood hazard categories along with their indexes and description has

274 been presented in Table 3. The critical flood depths $0.8,1.0$ and $3.5 \mathrm{~m}$ that applied for classification

275 of flood hazard assessment established based on the floor level of local buildings, neighboring 276 commercial infrastructure, and also elevation of single-storey building (Tingsanchali and Karim 277 2005, 2010). The present study adapted liner scale among linear, geometric, and exponential scales 278 for hazard classification as the linear scale has performed the best among others and also has been 279 recommended by previous published research studies. Eq. (6) is used to calculate hazard factor $280 \mathrm{H}_{F}$.

$$
H_{F}(i)=\left(\sum_{j=1}^{N_{D}} A(i, j) H_{I}(j)\right) / \sum_{j=1}^{N_{D}} A(i, j) \ldots(7)
$$

282 Where, i, j, $\mathrm{N}_{\mathrm{D}}$ and $\boldsymbol{H}_{\boldsymbol{I}}$ represent land unit identification number, depth category, total number of 283 depth categories and hazard index, respectively, whereas $\boldsymbol{A}(\boldsymbol{i}, \boldsymbol{j})$ belongs to land unit i under depth 284 category j.

\section{Model Performance Evaluation}

287 The study considers some of the most commonly used statistical parameters for the model's

288 performance evaluation. The hydrological model performance for discharge simulation was 289 evaluated using the Coefficient of Correlation (R), Nash Sutcliffe Efficiency (NSE), and Root 290 Mean Square Error (RMSE), and hydraulic model performance for the water level simulation was 291 evaluated using the Coefficient of Correlation (R), Relative Peak Error (RPE) and Volume Bias 292 (VB). Further detail on these statistics is reported in Shrestha and Lohpaisankrit 2017; Leta et al. 2932018.

\section{Results and Discussion}




\section{Calibration of 1D-hydrodynamic model}

297 Discharge and water level in 1D-hydrodynamic model were calibrated and validated for the period 298 of 4 years (2006-2009) and 2 years (2011-2012), respectively. The discharge and water level 299 stations located along main river (Ping river) are represented in Figure 1. The calibration 300 parameters presented in Table 4 tuned to improve hydrological model performance, and global 301 and local manning's ' $n$ ' values were adjusted for improvement of model's hydraulic performance.

302 The global and local manning's ' $n$ ' values are differentiated based on their "effecting scale", the 303 adjustment of global value has uniform effect on all river network, however, the local manning's

304 ' $n$ ' values are defined for adjustment of flow by changing the roughness of specific rivers or section 305 of river. The manning coefficient was adjusted between 0.29-0.50 during model calibration and 306 validation. Table 5 represents three statistical parameters (R, NSE, RMSE) for performance 307 evaluation of 1D hydrodynamic model for discharge simulation, and model' performance was 308 reasonably acceptable for calibration and validation at both stations, P.1 and P.67. The discharge 309 calibration and validation results are shown in Figures $3 a$ and $3 b$, and $4 a$ and $4 b$, respectively.

310 Generally, the simulated discharge hydrograph is well-matched with observations at both locations 311 (P.1 and P.67) for low and high periods during calibration, however, simulated discharge peak was 312 relatively underestimated for 2006 and 2009 years at both locations. Similar results pattern was

313 noticed at both locations during discharge validation. In case of water level calibration and 314 validation results, the model performance was relatively better at P.1 station compared to P.67, as 315 statistical parameters can be seen in Table 6. It might be because P.67 station is located at just 316 downstream of Mae Nam NGAT channel that starts at downstream of NGAT Dam, so the 317 simulated water level at P.67 station may not fully capture the controlled flow's pattern as it was 318 in real condition. However, the model performance is still quite acceptable and reliable for flood 319 inundation modeling at a larger scale considering limited data availability with coarser river 320 geometry. The water level calibration and validation results have been represented in Figures $3 \mathrm{c}$ 321 and $3 \mathrm{~d}$, and $4 \mathrm{c}$, and $4 \mathrm{~d}$, respectively. Multiple sources of uncertainties that exist and affect the 322 accuracy of river modeling results have been previously discussed for particularly in this region 323 by the author in Tansar et al., 2020. 


\section{Calibration of 2D-hydrodynamic model}

331 The 2D-hydrodynamic calibration was performed for the flood year 2011 by using MIKE Flood.

332 The 1D-2D hydrodynamic models were simulated for a period of 13 days (September 27, 2011 to

333 October 10, 2011) to reproduce flood inundation maps. The remotely sensed observed flood map 334 of 2011 year obtained from the Geo-Informatics and Space Technology Development Agency 335 (GISTDA), Thailand and compared with simulated inundation extent, as shown in Figure 5. The 336 area of observed and simulated flood inundation extent was $550.6 \mathrm{~km}^{2}$ and $489.6 \mathrm{~km}^{2}$, respectively. 337 Generally, the observed and simulated flood inundation extent reasonably matched well 338 throughout the inundated area. The flood inundations produced along the river network including 339 Ping river, Mae Nam NGAT, Mae Nam Taeng, Mae Wang, Mae Klang and Mae Nam Tha have 340 represented satisfactory better performance against the observed flood map. However, there are 341 some differences noticed between the observed and simulated extent around the lower section of 342 Mae Nam Kuang river and the observed flood extent relatively has a larger inundation area 343 compared to the simulated. It is reasonable to explain that the area along Mae Nam Kuang river in 344 Ban Thi and Mueang Lamphun districts also have a small network of small streams, located along 345 the Mae Nam Tha river that transferred the monsoon flow from the north-eastern part of this region 346 to the south-western areas. Occasionally, these streams also flooded during the monsoon period 347 and it might be possible that the simulated flood extent which does not cover by the overflow of 348 Mae Nam Tha river occurred because of these local streams. In addition, some cross-sections of 349 the rivers were taken from DEM (30m resolution) that could also lead to produce uncertainty in 350 flood inundation results. During this calibration process, the flood depth could not be calibrated in 351 the floodplain because of the unavailability of flood depth measurements. The average flood depth 352 of all floodplain was $1.86 \mathrm{~m}$. 


\section{Flood inundation mapping}

356 The flood inundation maps of return period 2, 5, 10, 25, 50 and 100 years are analyzed to compare 357 spatial distribution of flood extent and depth in different districts located in upper ping river basin,

358 as represented in Figure 6. The total flooded area against return period 2, 5, 10, 25, 50 and 100 359 years are $601.8 \mathrm{~km}^{2}, 743.0 \mathrm{~km}^{2}, 811.4 \mathrm{~km}^{2}, 878.3 \mathrm{~km}^{2}, 935.6 \mathrm{~km}^{2}$ and $996.9 \mathrm{~km}^{2}(3.94 \%$ of total 360 basin area), respectively, as represented in Table 7. Based on flood inundation results, some plain 361 areas are inundated along with the Ping, Mae Nam NGAT and Mae Nam Taeng rivers in upstream 362 districts (Chaing Dao, Phrao, Mae Taeng and Mae Rim) for the above-mentioned return periods 363 and the flood extent did not substantially expand during simulation of higher return periods (25, 36450,100 years), but the significant increase in flood depth was observed. It happened because the 365 topography of the neighboring areas around the river is plain and surrounded by mountains. The 366 major flood inundations took place in central part of upper ping river basin, and flood extent and 367 depth also significantly increased during higher return periods. The Ping and Mae Nam Kuang 368 rivers and some local streams located in central region overflowed and caused flooding in nine 369 districts (Mae Rim, San Sai, Hang Dong, San Pa Tong, Mueang Lamphun, Saraphi, Ban Thi, San 370 Kamphaeng), including in Chiang Mai district which is a major tourist place in northern part of 371 Thailand. The Ping river passes at the center of Chaing Mae district and the community and local 372 tourist spots are highly vulnerable to flood risk during peak monsoon period; especially, when the 373 upstream areas of upper ping basin receive continuous rainfall events followed by local rainfall 374 events in central regions. In such situation, the capacity of Ping river is unable to hold the flood 375 volume within the embankments and the neighboring areas are inundated. In case of lower part, 376 the substantial increase in flood extent and depth was observed from lower to higher return periods. 377 Approximately, the river Mai Li's was not flooded in lower return periods ( $2 \& 5$ years) in Ban

378 Hong and $\mathrm{Li}$ district and inundations made in neighboring areas with about $1 \mathrm{~m}$ depth during higher 379 return periods. The famous bigger Doi Tao lake is located in Hot and Doi Tao districts, in the 380 lower region of upper ping river basin. The flood volume that passed from central region to lower 381 region stored in Doi Tao lake with higher flood extent and depth (more than $4.5 \mathrm{~m}$ ) and this area is 382 almost less populated and not as much of susceptible to economic losses because of flooding. 


\section{Flood hazard assessment}

386 The flood hazard categories are classified based on criteria of the critical depths, as introduced by

387 Tingsanchali and Karim 2010, and a detailed description of flood hazards has been described in

388 Table 3. The flooded area of 2, 5, 10, 25, 50 and 100 years return periods are categorized under

389 different flood hazard levels in Table 7. The classification of flood results represents that the

390 overall major flood extent occurred under the "high hazard" category during all return periods,

391 followed by "very high hazard" and "low hazard" categories, and the least flooded area was classed

392 under "medium hazard" category. Besides the "very high hazard" category, the flood extent of

393 other categories was not significantly changed during all return periods, however, the major

394 increase in the flood extent area of "very high hazard" category observed from lower return period

395 (2-year) towards higher return period (100-year). During a 100-year return period, about $1.74 \%$

$396\left(439.8 \mathrm{~km}^{2}\right), 1.51 \%\left(382.9 \mathrm{~km}^{2}\right), 0.54 \%\left(137.6 \mathrm{~km}^{2}\right)$ and $0.14 \%\left(36.6 \mathrm{~km}^{2}\right)$ of the total flooded

397 area are classified under very high hazard, high hazard, low hazard, and medium hazard category,

398 respectively. Based on the flood hazard description in Table 3 and flood hazard results, most of

399 the local community and property existed in flood inundated areas are highly vulnerable to flood

400 damages during all return periods, and following by the inundated areas that can have severe flood

401 damages during higher return periods floods, because the flooding depth would be greater than

$4023.5 \mathrm{~m}$, classified as "extreme danger zone". In case of low and medium flood hazard levels, the

403 flooding water can enter surrounding buildings and can affect the daily routine activities of local

404 residents. In case of Thailand, the local administration departments, department of drainage and

405 sewerage, and department of disaster prevention and mitigation together with local residents take

406 some preliminary actions before monsoon season to avoid flood hazards and reduce the flood

407 damages to local infrastructure. However, the potential of such flood mitigation measures is

408 limited and can only help to reduce the flood impacts of low and medium hazard levels and need

409 to improve further for mitigation of higher hazard levels. The government needs to plan and

410 implement the state-of-the-art telemetry system in northern areas of Thailand that can help in flood

411 early warning system, real-time flood forecasting and decision support system for dissemination

412 of flood warning alarms to local community before flooding, as a precautionary step for flood 413 mitigations. 
414 Figure 7 represents the flood inundation area against 2, 5, 10, 25, 50 and 100 years return periods.

415 The flood inundation area is linearly increased against return periods from lower to higher return 416 periods floods.

[Table 7.]

418

\section{[Figure 7.]}

\section{Flood hazard classification at sub-district scale}

420 The 159 sub-districts located in upper ping river basin of Chiang Mai, Lamphun and Tak provinces 421 are classified into different flood hazard categories based on average flood depth of each sub-

422 district. Figure 8 represents the flood hazard zoning at sub-district scale (the smallest 423 administration unit in Thailand) for 2, 5, 10, 25, 50 and 100 years return periods. Overall, the 424 maximum sub-districts lie under "high hazard", followed by "very high hazard" and "medium 425 hazard" categories, and very few sub-districts classed under "low hazard" category during all 426 return periods. Generally, the assessment of classification concludes that most of the region in 427 upper ping river basin might be expected to face flood depth of $1-3.5 \mathrm{~m}$ followed by more than $4283.5 \mathrm{~m}$, and the flooding probability of less than $1 \mathrm{~m}$ is may possibly be less during monsoon season. 429 Specifically, the 122 sub-districts classified under high hazard category for a 2-year return period 430 and the number is gradually decreased to 104 for 100 -year return period. In contrast, the number 431 of subdistricts increased from 2 to 37, for 2- to 100-year return period. However, the classified 432 sub-districts for low and medium hazard levels remained almost constant during all return periods, 433 and subdistrict numbers varied from 5 to 9 in low hazard and 10 to 15 in medium hazard category.

434 All sub-districts located along ping river categorized under high hazard level during each return 435 period. In case of higher return periods, the flood depth in neighboring areas of ping river (upper, 436 central and lower section) increased and the classification of sub-districts changed from high 437 hazard to very high hazard category. Further, the sub-districts located along with Mae Nam Tha 438 and Mae Li's rivers were less anticipated to flooding and categorized under low and medium 439 hazard levels. It is also reasonable to explain that there was no flooding observed at the 440 downstream side of upper ping river basin during lower return periods ( $2 \& 5$ years). Based on 441 these results, the community and property existed along the ping river, especially in upper, central, 442 and lower sections, are highly vulnerable to flood risk during the monsoon season. In particular, 
443 Chiang Mai city and its surrounding areas are also classed under high hazard flood; as this city is

444 received a lot of tourists during the whole year and most of the economic activities in this region

445 are directly or indirectly interlinked with tourism. The fluvial and pluvial flooding has also been 446 reported in recent years in Chiang Mai city (Bicksler 2019). Comparatively, the probability of

447 flooding in distant areas is very less.

\section{[Figure 8.]}

\section{Capacity assessment of flood adaptation and mitigation measures}

451 This section evaluates the potential of local flood mitigation and adaptation measures at three 452 administration scales (1) National Government Level (2) Local Government Level (3) Community 453 Level (Table 8) and discusses various gaps that existed in flood adaptation measures at institutional

454 level and community scale. Also, future flood management recommendations are suggested for 455 the study area considering flood inundation and hazard results described in previous sections.

456 Multiple structural and non-structural flood mitigation measures are applied under each 457 administration level during flooding period to reduce the flood impacts in rural and urban areas, 458 however, the upper ping river basin is still severely facing flooding problems in monsoon period.

459 The maximum capacity of Ping river at P.1 station is $460 \mathrm{~m}^{3} / \mathrm{s}$, and additional discharge at this 460 location in monsoon period leads to flooding in downstream region especially Chiang Mai city 461 and its neighboring areas. However, to mitigate this problem, the "Ping River expansion project" 462 has been recently completed with its total length of $6 \mathrm{~km}$ in Chiang Mai city. Indeed, the city 463 municipality has only considered river's length within their jurisdiction because of fund limitation 464 and technically the flood risk now has been redistributed to downstream areas (Jarungrattanapong 465 and Manasboonphempool 2011). Based on river capacity and floodplain topography assessment 466 in 1D-2D hydrodynamic model, it is suggested to further expand Ping river's capacity of $16 \mathrm{~km}$ 467 following previous improved river length to potentially reduce future flood risk in this region.

468 The flood prediction capacity of currently available forecasting system is "seven hours" before it 469 hits the Chiang Mai City, and Hydrology and Water Management Center (HWMC) dissimilate 470 flood warnings to relevant government and communities (Jarungrattanapong and 471 Manasboonphempool 2011). However, the current system needs sufficient improvement with 
472 state-of-the-art real-time flood early warning system with high prediction accuracy and larger

473 flood forecasting capability. Following this, the flood alerts system also needs to be modified for 474 faster dissemination of flood warnings to all relevant stakeholders and local residents.

\section{Flood adaptation gaps and future recommendations}

477 Multiple gaps found in previous flood mitigation planning and management procedures of 478 government and local departments, and local stakeholders. Each department or community 479 completed their assigned tasks on an individual basis, either it is short-term or long-term, however, 480 now there is need to re-think and establish an integrated flood management framework in which 481 combined potential from all level of resources should be systematically managed and applied. 482 Moreover, the local community involvement is highly recommended and would be beneficial in 483 flood mitigation and adaptions process as their previous real flood experiences can help to develop 484 technically sound, practically applicable, socially acceptable, and economically viable structural 485 and non-structural flood mitigation strategies.

486 As local community now is habitual of annual floods, so sometimes they do not take flood 487 warnings seriously and also do not prepare themselves for disaster, resultantly, more tangible and 488 intangible flood damages have been occurred in past flood events. Moreover, some local residents 489 do not participate in individual and collective adaptation activities as they think that it is the 490 government's responsibility to protect people from flooding; there is need to educate and train 491 local community through disaster awareness and preparedness workshops to involve full human 492 resources potential during flood mitigation periods. A detailed practical research study is 493 recommended in future for the development of an integrated flood management framework with 494 the consideration of availability and limitation of local resources, administrative priorities and 495 conflicts, and preferences of local community' concerns. The study could provide guidelines to 496 update current administrative flood adaption and management set-up into an improved version for 497 better performance in future flood risk reduction. 
500 Flood inundation mapping and hazard assessment of the Upper Ping River basin performed for 501 different return periods with 1D-2D coupled hydrodynamic modelling approach to categorize 502 flooded areas into different hazard levels at the sub-district scale (the smallest administration unit

503 in Thailand). This study contributes to better utilization of flood adaption and mitigation measures

504 taken by multiple administration authorities before, during, and after floods for the protection of 505 local people, their properties, and other infrastructure.

506 The flood inundation and hazard analysis results represent that the sub-districts located around 507 Ping River are highly vulnerable to future floods, during low or high return periods in monsoon 508 season. The maximum flood inundation occurred at an area of $996.9 \mathrm{~km}^{2}$ (3.94\% of total basin 509 area) during the 100-year return period. The sub-districts are classified under "high hazard", 510 followed by "very high hazard" and "medium hazard" categories, and very few sub-districts

511 classed under "low hazard" category during all return periods. The severity of flooding problems

512 reduced for those sub-districts located at distant places from the river and vice versa.

513 Considering the flood problems, topographical characteristics of the basin, and locally available 514 flood mitigation resources, the current national and local administration needs to find an integrated 515 flood management approach with the better utilization of local resources to improve the current 516 flood protection system. The potential of existing flood early warning and information 517 dissemination systems needs to upgrade with state-of-the-art real-time flood forecasting and the 518 latest dissemination system.

\section{Acknowledgment}

520 The authors would like to acknowledge the support from Panya Consultants Co., Ltd. Thailand for 521 providing necessary data and technical support throughout the research. The authors would like to 522 thanks the Royal Irrigation Department (RID), Thailand, and Thai Meteorological Department 523 (TMD) for providing the hydrological and meteorological data for the study. The authors would 524 like to extend the word of thanks to the anonymous reviewers for the constructive comments and 525 suggestions.

526 Funding: This research study was not supported by any funding.

527 Conflicts of interest: The authors declare that they have no conflict of interest.

528 Availability of data and material: Not Applicable

529 Code availability: Not Applicable 


\section{References}

531 Abdessamed D, Abderrazak B (2019) Coupling HEC-RAS and HEC-HMS in rainfall-runoff 532 modeling and evaluating floodplain inundation maps in arid environments: case study of Ain 533 Sefra city, Ksour Mountain. SW of Algeria. Environ Earth Sci 78:1-17. 534 https://doi.org/10.1007/s12665-019-8604-6

535 Bates PD, De Roo APJ (2000) A simple raster-based model for flood inundation simulation. J $536 \quad$ Hydrol 236:54-77. https://doi.org/10.1016/S0022-1694(00)00278-X

537 Bicksler R (2019) The role of heritage conservation in disaster mitigation: a conceptual framework 538 for connecting heritage and flood management in Chiang Mai, Thailand. Urban Geogr 539 40:257-265. https://doi.org/10.1080/02723638.2018.1534568

540 Boonrawd K, Jothityangkoon C (2015) Mapping temporal extent of Chiang Mai floods using 541

542 coupled 1-D and quasi 2-D floodplain inundation models. Songklanakarin J Sci Technol 37:171-181

543 Brunner MI, Viviroli D, Sikorska AE, et al (2016) Flood type specific construction of synthetic 544 design hydrographs. J Am Water Resour Assoc 5:2-2. https://doi.org/10.1111/j.1752$545 \quad$ 1688.1969.tb04897.x

546 De Kok JL, Grossmann M (2010) Large-scale assessment of flood risk and the effects of mitigation 547 measures along the Elbe River. Nat Hazards 52:143-166. https://doi.org/10.1007/s11069$548 \quad 009-9363-6$

549 Farooq M, Shafique M, Khattak MS (2019) Flood hazard assessment and mapping of River Swat 550 using HEC-RAS 2D model and high-resolution 12-m TanDEM-X DEM (WorldDEM). Nat 551 Hazards 97:477-492. https://doi.org/10.1007/s11069-019-03638-9

552 Gale EL, Saunders MA (2013) The 2011 Thailand flood: Climate causes and return periods. 553 Weather 68:233-237. https://doi.org/10.1002/wea.2133

554 Haraguchi M, Lall U (2015) Flood risks and impacts: A case study of Thailand's floods in 2011 555 and research questions for supply chain decision making. Int J Disaster Risk Reduct 14:256$556 \quad 272$. https://doi.org/10.1016/j.ijdrr.2014.09.005 
557 Jarungrattanapong R, Manasboonphempool A (2011) Adaptive capacity of households and $558 \quad$ institutions in dealing with floods in Chiang Mai, Thailand

559 Jothityangkoon C, Hirunteeyakul C, Boonrawd K, Sivapalan M (2013) Assessing the impact of 560 climate and land use changes on extreme floods in a large tropical catchment. J Hydrol 561 490:88-105. https://doi.org/10.1016/j.jhydrol.2013.03.036

562 Jular P (2017) The 2011 Thailand Floods in The Lower Chao Phraya River Basin in Bangkok $563 \quad$ Metropolis

564 Komsai A, KINOUCHI T, WEI L (2016) Simulation of Extreme Flood and Inundation in 2011 in 565 the Upper Ping River Basin, Thailand. J Japan Soc Civ Eng Ser B1 (Hydraulic Eng 566 72:I_1183-I_1188.https://doi.org/10.2208/jscejhe.72.i_1183

567 Lebel L, Manuta JB, Garden P (2011) Institutional traps and vulnerability to changes in climate 568 and flood regimes in Thailand. Reg Environ Chang 11:45-58. https://doi.org/10.1007/s10113-010-0118-4

570 Lebel L, Sinh BT (2009) Risk Reduction or Redistribution? Flood Management in the Mekong 571

572 Region. Asian J Environ Disaster Manag - Focus Pro-active Risk Reduct Asia 01:25. https://doi.org/10.3850/s179392402009000040

573 Leta OT, El-Kadi AI, Dulai H, Ghazal KA (2018) Assessment of SWAT model performance in 574 575 simulating daily streamflow under rainfall data scarcity in Pacific island watersheds. Water 10:. https://doi.org/10.3390/w10111533

576 Mahmood S, Rahman A ur, Sajjad A (2019) Assessment of 2010 flood disaster causes and 577 damages in district Muzaffargarh, Central Indus Basin, Pakistan. Environ Earth Sci 78:1-11. $578 \quad$ https://doi.org/10.1007/s12665-019-8084-8

579 Mani P, Chatterjee C, Kumar R (2014) Flood hazard assessment with multiparameter approach 580 derived from coupled 1D and 2D hydrodynamic flow model. Nat Hazards 70:1553-1574. $581 \quad$ https://doi.org/10.1007/s11069-013-0891-8

582 Manuta J, Khrutmuang S, Huaisai D, Lebel L (2006) Institutionalized incapacities and practice in 583 flood disaster management in Thailand. Sci Cult 
584 Mapiam PP, Sriwongsitanon N (2009) Estimation of the URBS model parameters for flood 585 estimation of ungauged catchments in the upper Ping river basin, Thailand. ScienceAsia 35:49-56. https://doi.org/10.2306/scienceasia1513-1874.2009.35.049

587 M, Takeuchi K (2012) Assessment of flood hazard, vulnerability and risk of mid-eastern 588 Dhaka using DEM and 1D hydrodynamic model. Nat Hazards 61:757-770.

590 591

592 593

594 595 596 597

598 599 600

601 602 603

604 605 606 607 610 611 608 International Conference of GIT4NDM, 7-8 November 2012, Colombo, Sri Lanka

609 Saengsawang S, Pankhao P, Kaprom C, Sriwongsitanon N (2017) Projections of future rainfall for https://doi.org/10.1007/s11069-011-0060-х

Masud MB, Soni P, Shrestha S, Tripathi NK (2016) Changes in Climate Extremes over North Thailand, 1960-2099. J Climatol 2016:1-18. https://doi.org/10.1155/2016/4289454

Mediero L, Jiménez-Álvarez A, Garrote L (2010) Design flood hydrographs from the relationship between flood peak and volume. Hydrol Earth Syst Sci 14:2495-2505. https://doi.org/10.5194/hess-14-2495-2010

Nastiti KD, An H, Kim Y, Jung K (2018) Large-scale rainfall-runoff-inundation modeling for upper Citarum River watershed, Indonesia. Environ Earth Sci 77:1-12. https://doi.org/10.1007/s12665-018-7803-x

Nikitina E (2007) Institutional Capacity in Natural Disaster Risk Reduction: A Comparative Analysis of Institutions, National Policies, and Cooprative Responses to Floods in Asia. Final Report for APN project 2005-01-CMY-Nikitina

Onen F, Bagatur T (2017) Prediction of Flood Frequency Factor for Gumbel Distribution Using Regression and GEP Model. Arab J Sci Eng 42:3895-3906. https://doi.org/10.1007/s13369017-2507-1

Patel DP, Ramirez JA, Srivastava PK, et al (2017) Assessment of flood inundation mapping of Surat city by coupled 1D/2D hydrodynamic modeling: a case application of the new HECRAS 5. Nat Hazards 89:93-130. https://doi.org/10.1007/s11069-017-2956-6

607 Reda AG, Tripathi NK, Soni P, et al (2012) Climate Variability in Ping River Basin ,. In: 4th 610 the upper Ping River Basin using regression-based downscaling. Adv Clim Chang Res 8:256267. https://doi.org/10.1016/j.accre.2017.11.001 
612 Sarhadi A, Ausín MC, Wiper MP (2016) A New Time-varying Concept of Risk in a Changing 613 Climate. Sci Rep 6:1-7. https://doi.org/10.1038/srep35755

614 Sharma D, Babel MS (2013) Application of downscaled precipitation for hydrological climate615 change impact assessment in the upper Ping River Basin of Thailand. Clim Dyn 41:2589616 2602. https://doi.org/10.1007/s00382-013-1788-7

617 Shehata M, Mizunaga H (2018) Flash Flood Risk Assessment for Kyushu Island, Japan. Environ 618 Earth Sci 77:1-20. https://doi.org/10.1007/s12665-018-7250-8

619 Shrestha S, Lohpaisankrit W (2017) Flood hazard assessment under climate change scenarios in 620 the Yang River Basin, Thailand. Int J Sustain Built Environ 6:285-298. 621 https://doi.org/10.1016/j.ijsbe.2016.09.006

622 Sriwongsitanon N (2010) Flood forecasting system development for the upper Ping River basin. $623 \quad$ Kasetsart J - Nat Sci 44:717-731

624 Taesombat W, Sriwongsitanon N (2010) Flood investigation in the Upper Ping River basin using 625 mathematical models. Kasetsart J - Nat Sci 44:152-166

626 Takata K, Hanasaki N (2020) The effects of afforestation as an adaptation option: A case study in 627 the upper Chao Phraya River basin. Environ Res Lett 15:. https://doi.org/10.1088/1748$628 \quad 9326 / \mathrm{ab} 7462$

629 Tansar H, Babur M, Karnchanapaiboon SL (2020) Flood inundation modeling and hazard 630 assessment in Lower Ping River Basin using MIKE FLOOD. Arab J Geosci 13:. 631 https://doi.org/10.1007/s12517-020-05891-w

632 Tingsanchali T, Karim F (2010) Evaluation du danger d'inondation et zonage basé sur le risque 633 dans une plaine d'inondation tropicale: Cas de la Rivière Yom, Thaïlande. Hydrol Sci J $634 \quad 55: 145-161$. https://doi.org/10.1080/02626660903545987

635 Tingsanchali T, Karim MF (2005) Flood hazard and risk analysis in the southwest region of 636 Bangladesh. Hydrol Process 19:2055-2069. https://doi.org/10.1002/hyp.5666

637 UN (2003) Chao Phraya River Basin ( Thailand ) Population and socio-economic situation in the 638 Chao Phraya basin Socio economic conditions Land resources and use in the Chao Phraya 
$639 \quad$ basin. $1-9$

640 Wood SH, Ziegler AD (2008) Floodplain sediment from a 100-year-recurrence flood in 2005 of 641 the Ping River in northern Thailand. Hydrol Earth Syst Sci 12:959-973. 642 https://doi.org/10.5194/hess-12-959-2008

643 Yalcin E (2020) Assessing the impact of topography and land cover data resolutions on two644 dimensional HEC-RAS hydrodynamic model simulations for urban flood hazard analysis.

645 Nat Hazards 101:995-1017. https://doi.org/10.1007/s11069-020-03906-z

646 Yin J, Yu D, Yin Z, et al (2013) Multiple scenario analyses of Huangpu River flooding using a 647 1D/2D coupled flood inundation model. Nat Hazards 66:577-589. 648 https://doi.org/10.1007/s11069-012-0501-1

649 Zhang Y, Wang Y, Zhang Y, et al (2021) Multi-scenario flash flood hazard assessment based on 650 rainfall-runoff modeling and flood inundation modeling: a case study. Nat Hazards 105:967651 981. https://doi.org/10.1007/s11069-020-04345-6 


\section{Figures}

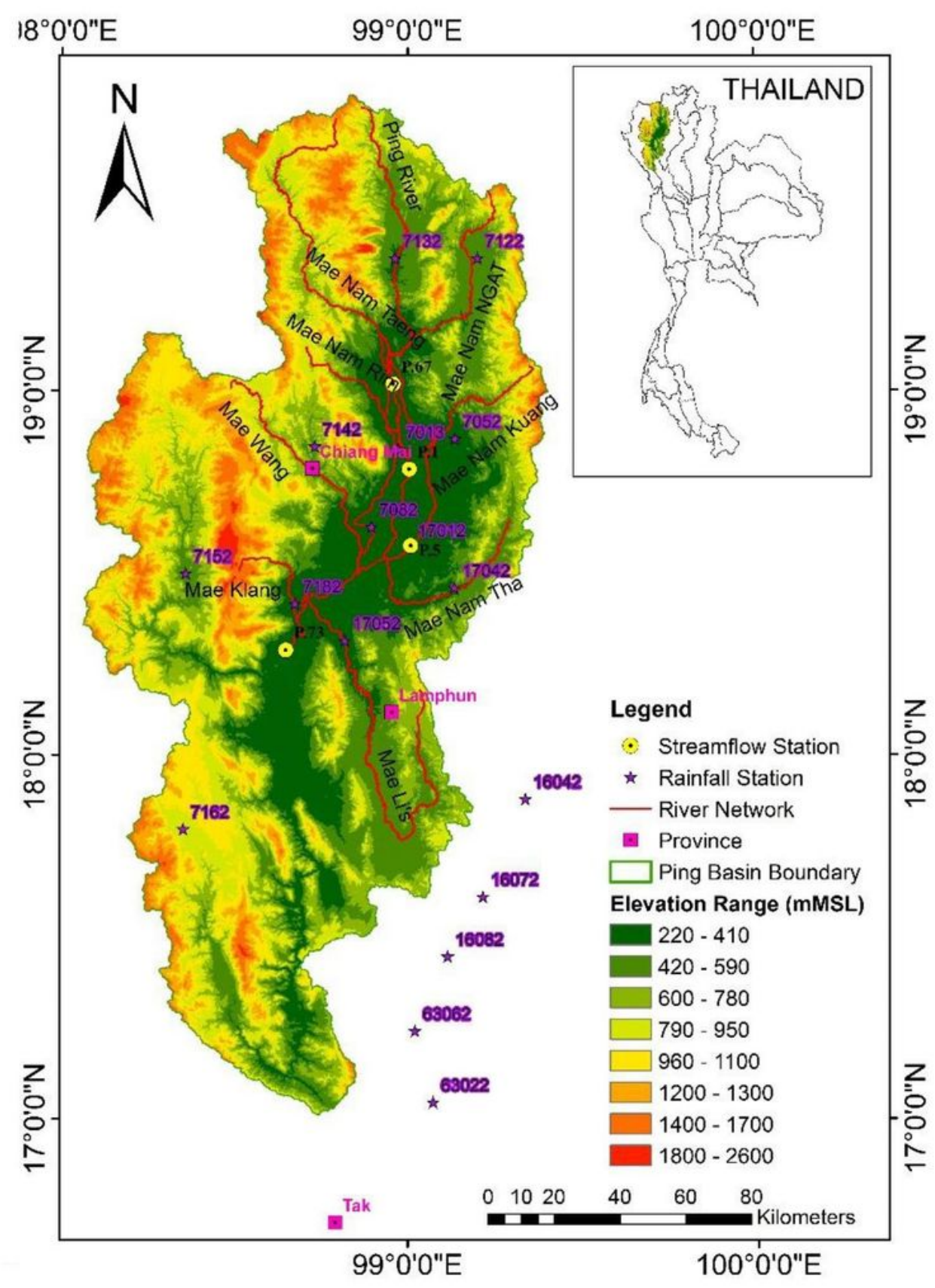

Figure 1

Figure 1

Location map of study area with hydro-meteorological stations in Upper Ping River Basin, Thailand Note: The designations employed and the presentation of the material on this map do not imply the expression of any opinion whatsoever on the part of Research Square concerning the legal status of any country, 
territory, city or area or of its authorities, or concerning the delimitation of its frontiers or boundaries. This map has been provided by the authors.

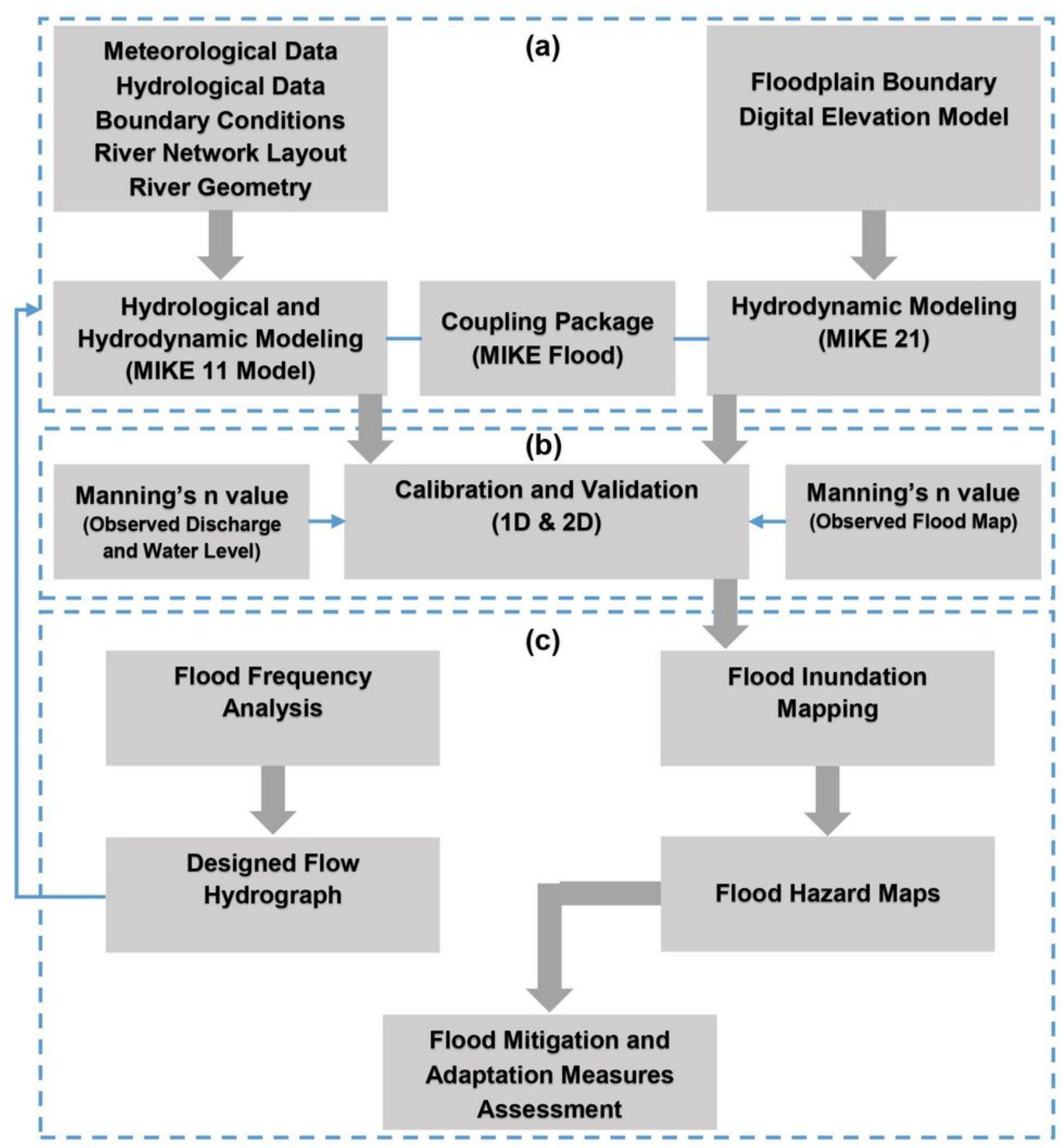

Figure 2

Figure 2

Methodological Framework for flood hazard assessment and adaptation measures 

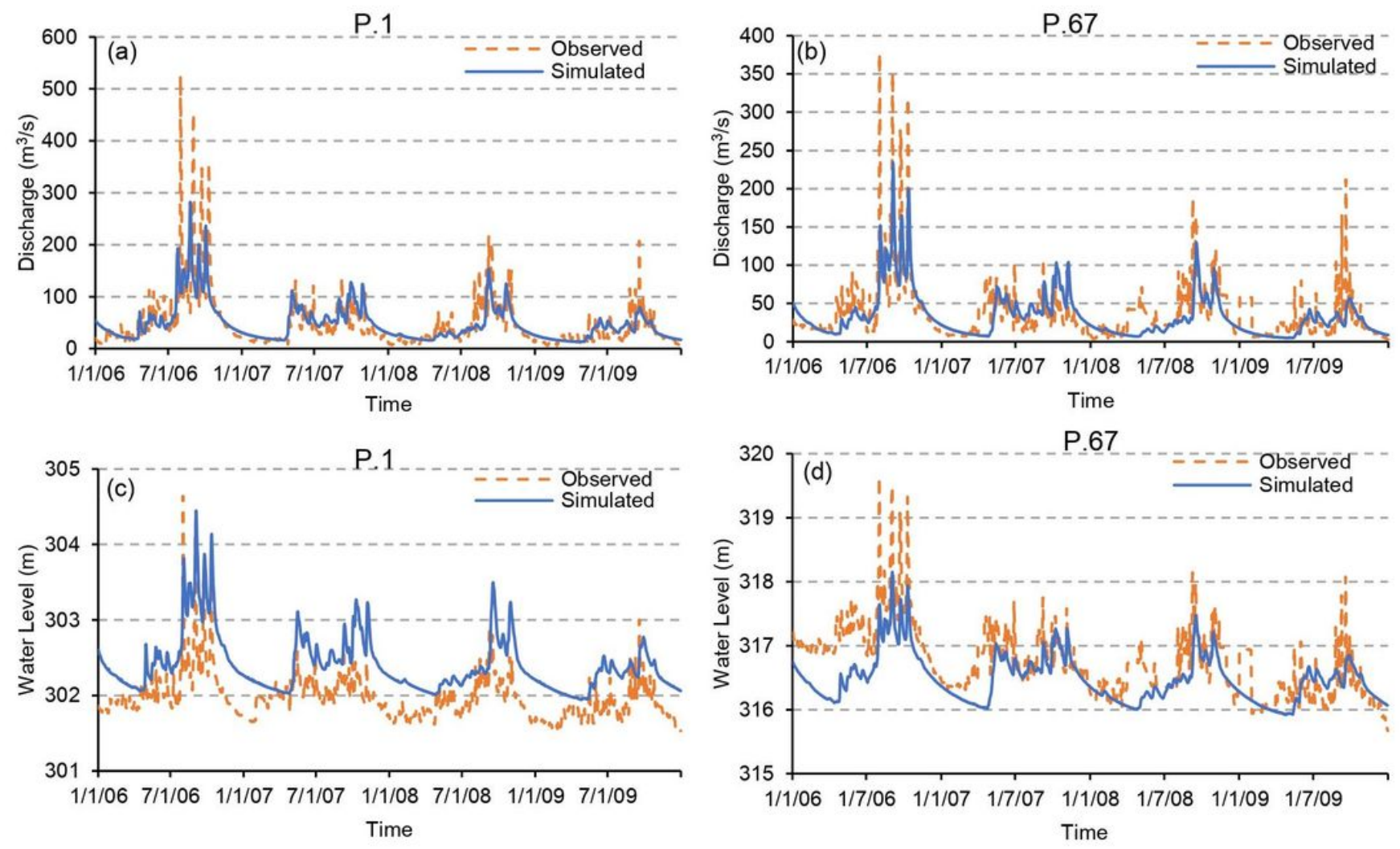

Figure 3

\section{Figure 3}

Calibration results of discharge at (a) P.1 and (b) P.67 and water level at (c) P.1 and (d) P.67 

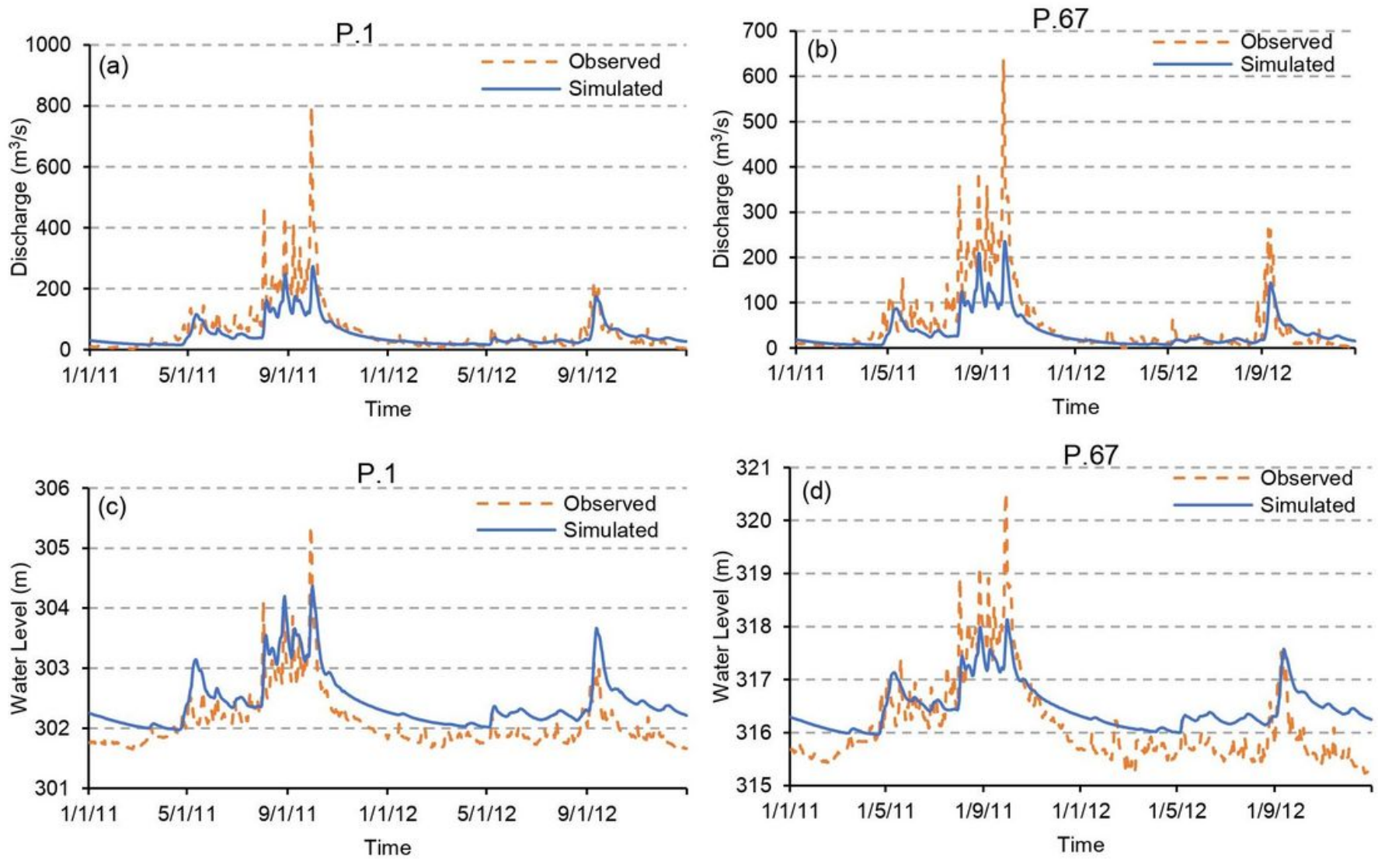

Figure 4

\section{Figure 4}

Validation results of discharge at (a) P.1 and (b) P.67 and water level at (c) P.1 and (d) P.67 


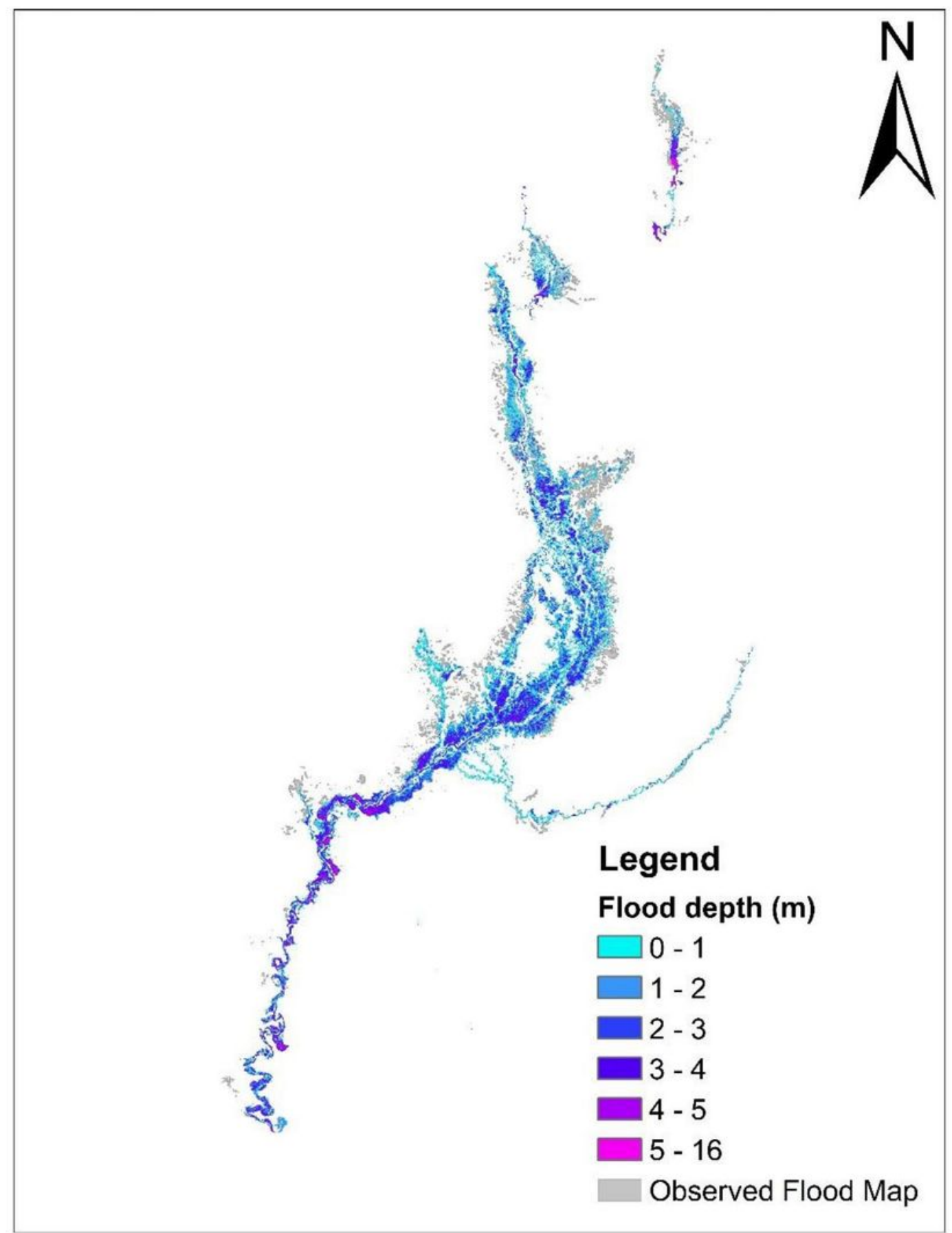

Figure 5

\section{Figure 5}

Calibration results of 2D-hydrodynamic model Note: The designations employed and the presentation of the material on this map do not imply the expression of any opinion whatsoever on the part of Research Square concerning the legal status of any country, territory, city or area or of its authorities, or concerning the delimitation of its frontiers or boundaries. This map has been provided by the authors. 


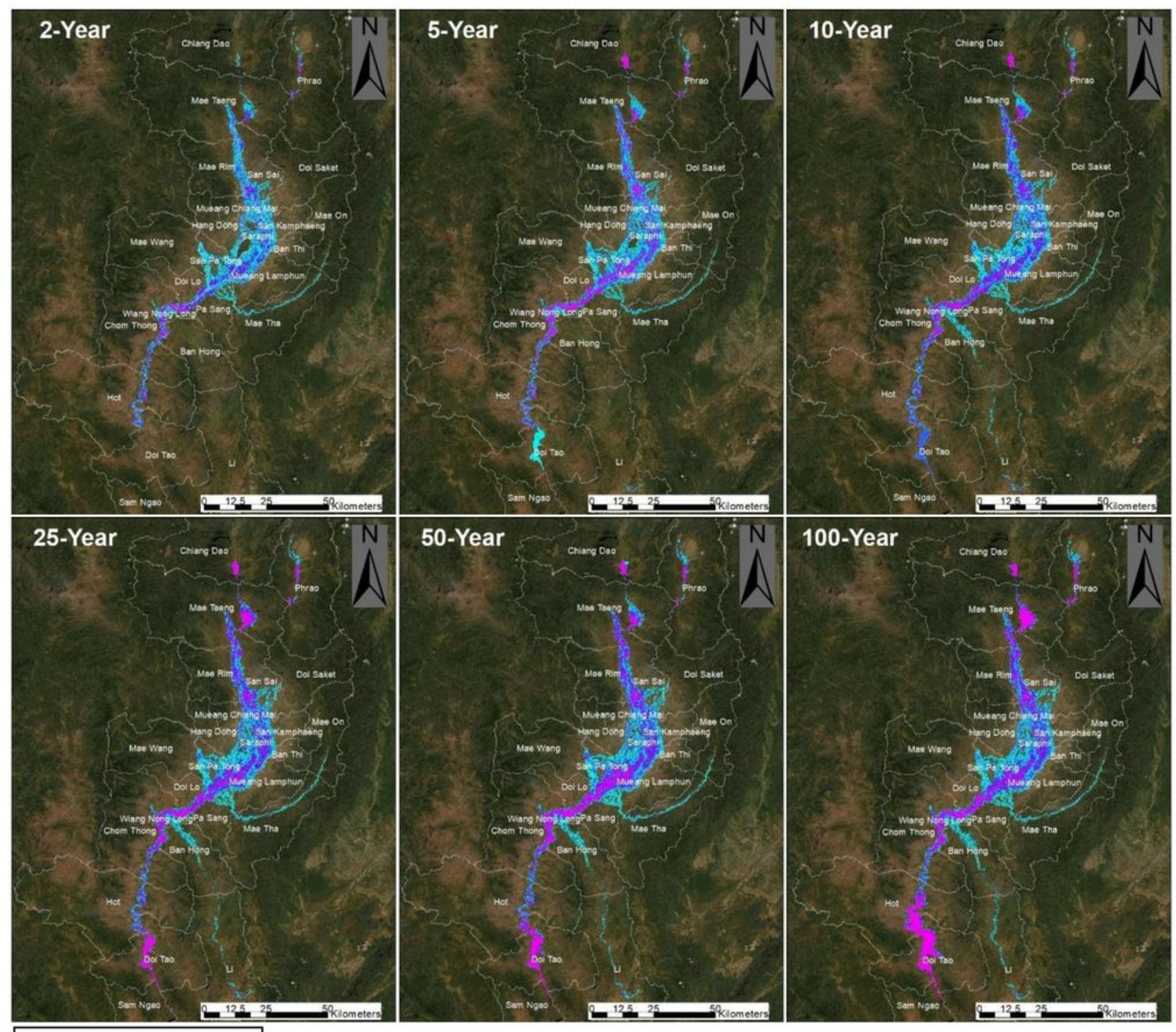

\begin{tabular}{|l}
\hline Legend \\
District \\
Flood depth $(\mathrm{m})$ \\
\hline Less than 1.5 \\
$1.5-3$ \\
$3-4.5$ \\
Greater than 4.5
\end{tabular}

Figure 6

\section{Figure 6}

Flood inundation depth for different return periods Note: The designations employed and the presentation of the material on this map do not imply the expression of any opinion whatsoever on the part of Research Square concerning the legal status of any country, territory, city or area or of its authorities, or concerning the delimitation of its frontiers or boundaries. This map has been provided by the authors. 


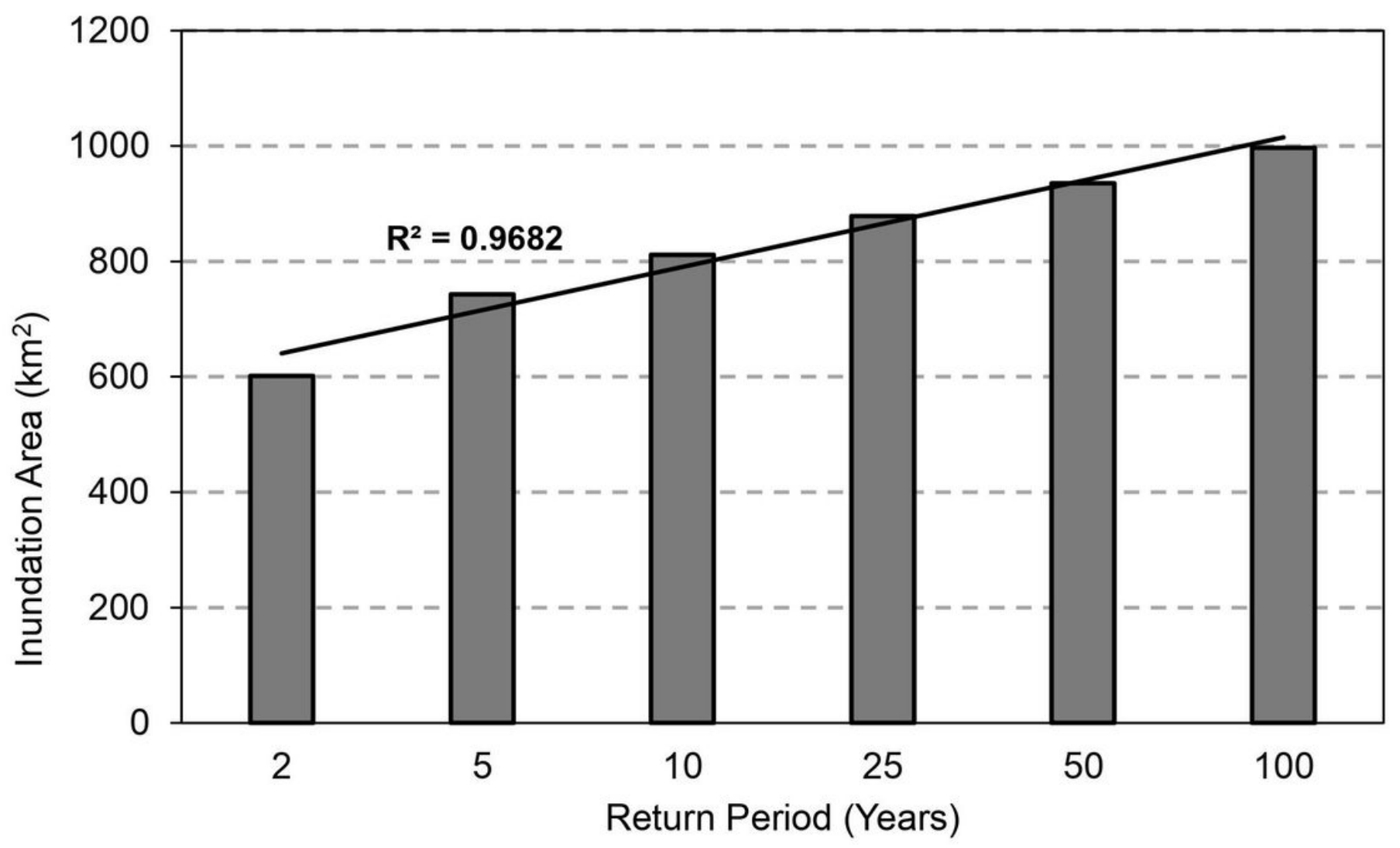

Figure 7

Figure 7

Comparison of inundation area against different return periods 


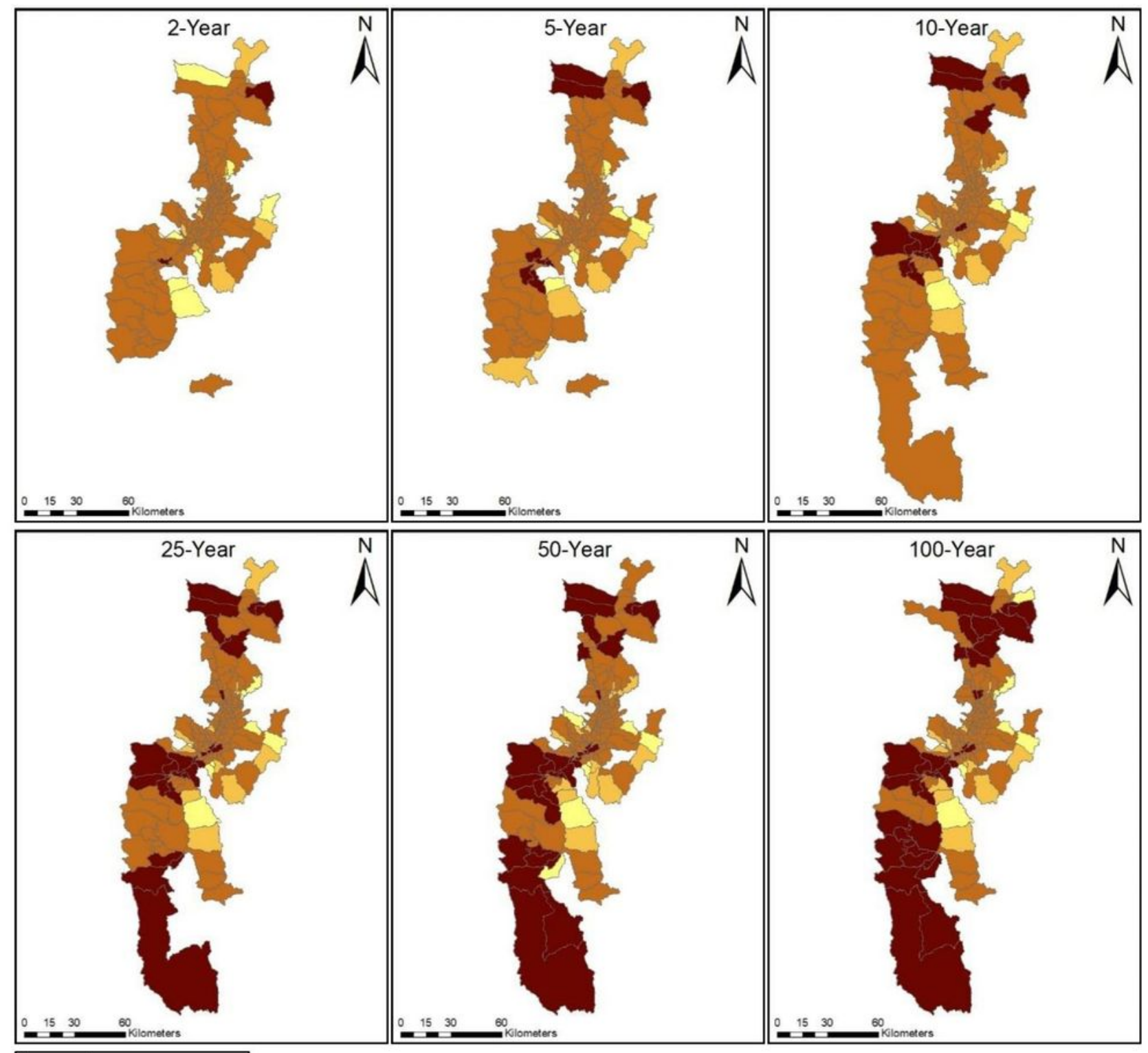

\section{Legend}

Flood hazard

Low hazard

Medium hazard

High hazard

Very high hazard

Figure 8

\section{Figure 8}

Flood hazard assessment of sub-districts for different return periods Note: The designations employed and the presentation of the material on this map do not imply the expression of any opinion whatsoever on the part of Research Square concerning the legal status of any country, territory, city or area or of its authorities, or concerning the delimitation of its frontiers or boundaries. This map has been provided by the authors. 


\section{Supplementary Files}

This is a list of supplementary files associated with this preprint. Click to download.

- Tables.docx 